\title{
ESCRITURA TOPOGRÁFICA Y ARTEALIZACIÓN DEL PAISAJE EN CHRONICLES OF THE HOSTILE SUN DE DIONNE BRAND
}

\author{
AZUCENA GALETTINI \\ Universidad Nacional de La Plata \\ agalettini@gmail.com \\ ORCID: 0000-0002-2518-0509
}

\section{RESUMEN}

El poemario Chronicles of the Hostile Sun (1984) de la autora trinitense Dionne Brand, que reside en Canadá desde la década de 1970, evoca la revolución de Granada que ocurrió entre 1979-1983 y la ocupación estadounidense de la isla durante la operación denominada «Urgent Fury» en octubre de 1983. En el presente trabajo se explora cómo Brand construye lo que aquí denominamos una «escritura topográfica» para dar cuenta del proceso de artealización (Roger 2007) que todo paisaje conlleva, poniendo el eje en las luchas políticas que esta estetización esconde. Brand pone en evidencia en su poesía cómo opera su propia «pantalla-tamiz» (Foster 1988) a la hora de mirar el Caribe, así como también la construcción estereotipada y reduccionista de quienes lo ven sólo como fuente de consumo.

PALABRAS CLAVE: escritura topográfica, paisaje, poesía caribeña, política, Dionne Brand.

\section{TOPOGRAPHIC WRITING AND LANDSCAPE ARTELIZATION IN CHRONICLES OF THE HOSTILE SUN, BY DIONNE BRAND}

\section{ABSTRACT}

Chronicles of the Hostile Sun (1984), poetry collection by Dionne Brand, Trinitarian author who has been living in Canada since 1970, evokes the Grenadian Revolution, which took place between 1979-1983 and the military occupation by the United States during the operation "Urgent Fury, in October 1983. In this paper we explore how Brand constructs what we named "topographic writing" to describe the process of artelization (Roger 2007) that every landscape entails, stressing the political struggles that this aestheticization hides. In her poetry, Brand makes explicit the work of her own "screen" (Foster 1988) when looking at the Caribbean, as well as the stereotyped and reductionist construction of those who only see the region as a source for consumption.

KEYWORDS: topographic writing, landscape, Caribbean poetry, Dionne Brand.

Un mar de aguas transparentes y cálidas, arena casi blanca que no quema los pies, palmeras que ofrecen gustosas su sombra y sus frutos. Esa imagen idealizada que surge ante la mera evocación de la palabra «Caribe» es un fantasma que acecha a la literatura de la región, en especial la de habla inglesa. Las nociones espaciales resultan vitales para pensar el Caribe, pues ha marcado las cosmovisiones filosóficas con respecto a la región: desde Antonio Pedreira (1942 [1934]) y su visión del mar como una fuente de aislamiento a Édouard 
Glissant (1981, 2006 [1997]), quien verá ese mismo elemento como una representación del «genio refractante» que define a la región (Braithwaite y Glissant 2010) hasta Antonio Benitez Rojo (1989), para quien el mar es aquello que une y hermana las islas y postula que el Caribe se extiende más allá de sí mismo, como un meta-archipiélago que desborda sus límites, postura que retoma Ana Pizarro (2002) al sostener que en la diáspora, el archipiélago caribeño extiende sus fronteras hacia el exterior.

Así como la geografía es el punto de partida de los pensadores caribeños para construir cosmovisiones, también lo es en poesía, como estipula Kamau Braithwaite al confesar que necesitó contar los orígenes de la situación geofísica natural en la que se encontraba para poder dar origen a su propia poesía (Braithwaite y Glissant 2010). De esta forma, se marca el vínculo entre paisaje y poesía, no como fuente de inspiración sino como eje fundamental a partir del cual escribir. De hecho, la relación entre ambos en el Caribe anglófono resulta insoslayable. Desde los primeros poemas de la región escritos por la clase señorial blanca que, preocupados en glorificar la aventura en el Caribe para el público que se encontraba en las Islas Británicas, alababan e idealizaban la belleza natural del archipiélago, ${ }^{1}$ pasando por la imagen mítica de playa desierta, propia de la postal caribeña, que surgió como respuesta a la búsqueda del imperialismo romántico del siglo XIX, hasta la poesía de sesgo nacionalista de la primera mitad del siglo XX que cantaba las loas de la «madre patria» e imitaba el orgullo que la poesía inglesa mostraba ante su naturaleza (Breiner 1998: 109). El quiebre surgirá luego de la Segunda Guerra Mundial, cuando se inicie un gran proceso migratorio del Caribe al Reino Unido, hecho generará un cambio radical en la poesía de las Antillas. ${ }^{2}$ Por un lado, porque buena parte de los intelectuales parten en búsqueda de mejores oportunidades. Por otro, porque una vez instalados en la metrópolis muchos dejaron de escribir poesía para volcarse a la narrativa, que les brindaba mejores posibilidades de publicación. Los marcados procesos migratorios implicaron un debate sobre lo que podía ser considerado

\footnotetext{
${ }^{1}$ A modo de ejemplo, unos versos del poeta James Montgomery (1771-1854) de su The West Indies, and Other Poems (1810), libro publicado en honor a la abolición de la esclavitud: «Where first his drooping sails / Columbus furl'd / And sweetly rested in another world, / Amidst the heaven reflecting ocean, smiles / A constellation of elysian isles; / Fair as Orion when he mounts on high, / Sparkling with midnight splendour from the sky: /.../ Earth from her lap perennial verdure pours, / Ambrosial fruits, and amaranthine flowers; / Nature in all the pomp of beauty reigns...» (Montgomery, 1810: 11 en Baugh 2001: 227) («Donde por primera vez / Colón izó sus velas/ y dulcemente descansó en otro mundo / entre el océano que refleja el cielo sonríe / Una constelación de islas elíseas / Bellas como Orión cuando se eleva/ Resplandeciente con el brillo del cielo de medianoche [...] / La tierra de su regazo verdor perenne vierte/ frutas como ambrosía y flores eternas / La naturaleza en toda la pompa de la belleza, reina»).

${ }^{2}$ Luego de la Segunda Guerra Mundial, la necesidad de reconstruir una Inglaterra devastada por la guerra y la carencia de mano de obra propulsaron la British Nationality Act (1948), que estipulaba que todo ciudadano de la Commonwealth era considerado británico, por lo cual podía ingresar en las islas del Reino Unido sin ningún tipo de restricción.
} 
«literatura caribeña». La poesía de este período exploró críticamente la idea de lo que significa ser «caribeño» y da cuenta de la difícil elección entre el «allí» y el «aquí» (Baugh 2001: 264). Será durante las décadas de 1950 a 1970 que surja el llamado «boom», es decir, que empiece a circular la literatura del Caribe anglófono en Londres y se establezca lo que aún hoy se considera el «canon» para la región, con la publicación de autores como V. S. Naipaul, George Lamming, Sam Selvon, Wilson Harris, Derek Walcott y Kamau Brathwaite.

La relación con el paisaje del Caribe en esta generación ya no será imitativa. El paisaje no será simplemente un telón de fondo que aporte exotismo. Incluso si parte de reducción a sus elementos: la playa, las olas, el mar, los frutos, se llega a la presencia del sujeto y a la exposición de una postura política: «... un recordatorio de que la urgencia de comenzar con lo más elemental suele ser una respuesta a presiones que politizan la poesía» (Breiner 1998: 205). ${ }^{3}$ Desde este punto de vista, es posible afirmar que la poesía del Boom politiza el paisaje al ser expresión de las relaciones intersubjetivas y de poder presentes en el espacio que describen.

Esta visión resulta vital para pensar cómo las generaciones subsiguientes establecen en su poesía relaciones con el paisaje. En el presente trabajo, nos detendremos en el poemario Chronicles of the Hostile Sun (1984), de la autora trinitense residente en Canadá Dionne Brand (1953), que pertenece a la generación posterior a la denominada «del Boom». En él observaremos cómo lenguaje y espacio se encuentran intrínsecamente ligados; el paisaje no reemplaza a la musa ni es una fuente de «caribeñidad» que vuelva aceptable la poesía para ser consumida for export, será un eje fundamental a partir del cual escribir, uno que configura a la escritura misma y que permitirá dar cuenta de la construcción ideológica de la autora.

\section{PAISAJE Y ESCRITURA TOPOGRÁFICA}

Como ya se ha mencionado, la categoría «paisaje» resulta vital para pensar la poesía de las Antillas de habla inglesa. Este concepto permite articular espacio y estética, dado que el paisaje opera, en términos de Alain Roger (2007:21-25) como artealización del espacio, y esa estetización surge a partir de la estructuración de la mirada que «...está saturada de una profusión de modelos, latentes, arraigados $y$, por ende insospechados [...] que actúan en silencio para en cada momento moldear nuestra experiencia, perceptiva o no» (Roger 2007: 20).

La visión de Roger sobre el paisaje sigue la tradición de la «nueva geografía cultural» que surgió a finales de la década de 1980, que retoma de la geografía humanista el enfoque hermenéutico en que el paisaje presenta un valor simbólico y puede ser leído en tanto texto, por lo que predomina la interpretación de la experiencia de los sujetos que lo habitan o de los observadores externos (Souto

\footnotetext{
${ }^{3}$ Traducción propia.
} 
2011: 138). El geógrafo inglés Denis Cosgrove, perteneciente a la corriente de la geografía cultural, enfatiza la importancia de no perder de vista el plano material del paisaje, por lo que traza su devenir histórico desde una perspectiva crítica y materialista. Según este pensador (2002: 68), el espectador ejerce un poder imaginativo al convertir el espacio material en paisaje. Notoriamente influenciado por John Berger (2000 [1972]), Cosgrove (1984) considera que el paisaje se constituye como un «modo de ver» burgués durante los siglos XV y XVI, como una operación asociada con la apropiación y mercantilización de la tierra. Así, en la ciudad renacentista italiana, mientras el paisaje se presentaba como representación de la naturaleza, permitía sostener la ilusión de que no implicaba una mercantilización de la tierra, sino que era muestra de un mundo en el que la vida estaba en armonía con la naturaleza. En esa línea también Cosgrove analiza la estetización de los paisajes de la campiña inglesa: como representación velada de la propiedad, la complacencia del patricio que retrata (o mejor dicho, manda a retratar) su posesión (2004: 61).

Ahora bien, si todo paisaje puede ser pensado en términos de artealización, Cosgrove (2004: 68) sostiene que esa estetización le otorga a éste la capacidad de funcionar como un velo que esconde relaciones sociales históricamente específicas bajo el parejo y estético manto de «naturaleza», ocultando la mano de obra que lo produce y mantiene, situando lo histórico más allá de toda reflexión crítica (Cosgrove 2002: 79-80). Es posible leer allí los ecos de Raymond Williams y su El campo y la ciudad (2001 [1973]), donde sostiene que el paisaje implica siempre separación y observación (163); se establece así una distancia social, en que la construcción paisajística borra el valor productivo presente en ese terreno que se decide recortar como un paisaje.

Sin duda, el paisaje es uno de los lugares privilegiados para verificar y medir el poder estético que el arte ejerce sobre la mirada (Roger 2007: 20), que trae consigo sus modelos y prejuicios, es decir, que en él se observa siempre «un punto de vista y un espectador» (Aliata y Silvestri 2001: 10). En el presente ensayo, el concepto de paisaje tendrá un origen humano y artístico en el que el arte opera como mediador, «el meta de la metafísica paisajística» (Roger 2007: 14), no obstante, estará siempre en relación con el espacio físico, material; es decir, las categorías espaciales no serán metafóricas ni enunciativas, se trabajará siempre con la articulación entre la espacialidad en la que los individuos negocian y luchan, y la artealización entendida no como una estetización que recubra esas tensiones, sino que construya los espacios con todas ellas en mente.

Si bien esta manera de concebir el paisaje está marcada por el perspectivismo cartesiano, propio del Renacimiento y no es trasladable a todo momento histórico [seguimos a Jay (1988), Crary (1988) y Bryson (1988)] esta relación entre paisaje y poder es vital para pensar la poesía de Dionne Brand. La construcción paisajística que esta poeta establece, su artealización para volver a los términos de Roger, está marcada por lo aquí denominaremos escritura topográfica. Esta categoría se encuentra inspirada por la idea de «topografía» 
según la plantea J. Hillis Miller (1995), para quien el término se ha transformado en el nombre que designa aquello que es representado en el mapa (entendiendo a «mapa» como representación cartográfica), pero sin ninguna referencia a la escritura u otro medio de representación. Dado que originalmente la topografía significaba la creación de un equivalente del paisaje en palabras, Miller recupera la etimología original para plantear que en «topografía» confluye tanto el acto de «revelar» como el de «crear». Con la noción de escritura topográfica no nos referimos a la mera descripción del paisaje. La dimensión espacial trasciende el rol de «escenario» o de fuente inspiradora. El paisaje es, en sí mismo, un «material», entendido este en los términos adornianos, todo aquello que se le ofrece al artista para la creación, pero no en tanto contenido, sino que las formas mismas pueden ser material (Adorno 2004 [1970]: 251). El espacio, entonces, en tanto material, no pasa a ser algo externo a la escritura, es tan intrínseco a la creación poética de esta autora como la noción de ritmo. La escritura topográfica implica que el espacio se inscribe en el acto poético en sí. No hay escenario, puesta en escena, telón de fondo: la poesía es el espacio en el que el paisaje se describe, revela, funda y reinventa.

La mirada paisajística que Brand construye supera la mera creación de un paisaje. Buscar leerlo como un texto no implica intentar interpretarlo, sino que las claves, las rupturas y continuidades que se persiguen como devolución a su mirada ponen en evidencia, a su vez, que el paisaje es un texto, en tanto construcción poética pero también como un armado ceñido a los velos de la tradición (Breiner 1998). Estos son parte de lo que la mirada trae consigo, lo que Hal Foster, reinterpretando la "pantalla-tamiz» de Lacan, concibe como la reserva cultural de la que cada imagen es un ejemplo, entendiendo imagen como aquello que se conforma luego de domar la mirada. La "pantalla-tamiz» puede ser, entonces, las convenciones del arte, los esquemas de representación, los códigos de la cultura visual (Foster 2001: 143). Brand construye su escritura topográfica poniendo en escena esos velos, señalando siempre esos códigos y prejuicios constitutivos. No se trata de una mirada ingenua que cree poder dar una descripción mimética ni que el lenguaje puede ser un medio transparente de representación, sino, «el proyecto estético para abrir forma y lengua» (Masiello 2013: 99).

Nos proponemos, entonces, ver cómo en Chronicles... de Dionne Brand esa escritura topográfica implica dar cuenta del proceso de artealización que todo paisaje conlleva para poner el eje en las luchas políticas que ésta esconde. Brand pone en evidencia en su poesía cómo opera su propia «pantalla-tamiz» a la hora de mirar el Caribe, así como también la construcción estereotipada y reduccionista de quienes lo ven sólo como fuente de consumo. 


\section{ARTEALIZACIÓN POLÍTICA DEL PAISAJE}

This is how I know struggle, know it like a landscaper. Dionne Brand, «St. Mary's State», Sans souci

Chronicles of a Hostile Sun es el cuarto poemario de Dionne Brand, poeta y novelista, pero aun así forma parte de lo que se considera su «obra temprana», como lo atestigua su publicación conjunta en el libro Chronicles, Early Works en 2011, ${ }^{4}$ y como tal, ha recibido muy poca atención de la crítica, a diferencia de las obras posteriores, como No Language is Neutral, Land to Light on, Ossuaries, o toda su obra narrativa.

En Chronicles of a Hostile Sun se evoca la revolución de Granada que ocurrió entre 1979-1983 y la ocupación estadounidense de la isla durante la operación denominada «Urgent Fury» en octubre de 1983. Brand formaba parte del Gobierno Revolucionario del Pueblo en el momento de esta invasión y es un hecho que evidentemente dejó una honda marca en su obra, pues es un tema recurrente en ella. ${ }^{5}$

Este libro se divide en tres partes: «Languages», «Sieges» y «Military Occupations». Es posible asociar esas tres secciones con las temporalidades que se observan en el poemario: previa a la invasión, la invasión en sí misma y la post-invasión; sin embargo, flashbacks durante las dos últimas partes generan cruces que desmienten esa división taxativa.

Si en el primer poemario de Brand, Primitive Offensive, se observaba una preocupación con respecto a los orígenes y el linaje, en Chronicles of the Hostile Sun, la creación de un linaje propio parece estar asociada con el sueño revolucionario. El filtro desde el cual todo el poemario es construido es el de la lucha política y su fracaso. En este libro se establece una relación ambigua con paisaje, percibido como extensión del sujeto, pero también como amenaza; tensión que Clarke (2012: 155) define como el «antiromanticismo romántico» de Brand por la ambivalencia en su obra entre el placer y la desconfianza de una localización. En contraposición con esa visión, elegimos pensar esa suerte de

\footnotetext{
${ }^{4}$ En ese libro reúne tres poemarios: Primitive Offensive, Winter Epigrams and Epigrams to Ernesto Cardenal in Defense of Claudia (1983) y Chronicles of the Hostile Sun (1984). Mencionamos que es este último es su cuarto poemario porque previo a Primitive Offensive, había publicado 'Fore Day Morning (1978). Sin embargo, hasta la fecha 'Fore day... no ha sido reeditado y no forma parte del volumen Chronicles. Early Works (2011). En esa colección de «obra temprana», Brand, como ella misma sostiene en una nota aclaratoria, ha debido modificar y corregir los poemas, aunque siempre en la búsqueda de preservar aquello que había hecho inicialmente. Sobre Primitive... afirma que: «[it] needed some tightening, some weeding of lines...». Se observa, entonces, que la propia Brand decidió excluir 'Fore Day... y sí reeditar Primitive..., aun cuando consideraba que este último requería cierto trabajo de edición. Por consiguiente, aunque ni en esa nota ni en la introducción de Leslie Sanders se explicite el porqué de la exclusión de 'Fore Day..., es posible leer allí el gesto autoral fundante que establece como primera obra Primitive Offensive.

${ }^{5}$ A eso se refiere Clarke (2012) cuando afirma que Brand necesitó atravesar un infierno dantesco para conformar su estilo.
} 
ambivalencia con respecto al entorno natural como la configuración de una mirada paisajística según el marco específico desde el cual opera el proceso de artealización (Roger 2007), marco que en Brand siempre se encuentra teñido por su ideología. Esta ambivalencia se hace evidente ya desde el primer poema «Night - Mt. Panby Beach - 25 March 1983» (96-98). ${ }^{6}$

Mt. Panby Beach - 25 March 1983

Many years from now

this surf, this night

of American war ships in Barbados,

Mt. Panby beach with its reef

and sea urchins,

this night of tension

and utterly huge ocean,

I see Orion like an imperialist .

straddle the half sky,

a drizzle of rain,

wondering how it is possible

to be tearful and fearless together,

drink another beer,

this night may make it to a poem,

how

the surf so unevenly even

surprises me,

the foam shooting sideways along the rock,

something red blinking far in the ocean

Rose belongs to the militia,

the militia is out

rutting in the drizzle and sand,

they are comfy at Camp David,

we are wet and always startled

though for once we have guns,

For this the boy upstairs

-look at his face

so serious and tender-

For this the boy upstairs

must put on his boots and his greens,

and wake me up at 4 a.m.

coming home

First night of the alert,

all of us in Managua and on Mome Rouge Bay

were insomniac,

forgetting bathing suits and rum punches,

anything we ate tasted like dirt,

like dirt again,

and to think, in the afternoon,

the shallow bay held all our talk

${ }^{6}$ Todas las citas pertenecen a la edición Chronicles, Early Works. Waterloo, Canadá, Wilfrid Laurier University Press, 2011. 
and now the evening

and the radio silenced,

in Matagalpa,

on the market hill,

we bawled at the air,

someone must go through something for this,

only this night

afraid of the sea and what's in it

and the reef

with its molluscs and shooting tide,

what a sound!

like a shot part the ear,

the salivary foam on the teeth of the sand,

what a sound!

fresh and frightening,

snatching what's ours again

You cannot swim on Mt. Panby beach

but you can sit

and drink a beer in the evening,

and let your eyes fool you

about the green flash of the descending sun,

this night,

Orion's sword - a satellite,

this bird of night

lifted itself up around the houses on the hill and the fort,

you'd never think

that three hours ago it lay pink

and purpling, hugging the town,

even kissing us,

now, that preying bird of a night

gives comfort to spy planes

Mt. Panby

ditches in the sand,

the spitting surf,

it may not be enough time

to drink a beer

and it's the only thing that this beach is good for except for

looking at St. Georges,

and only the fort and the church

they have classified photographs,

these American warships

secret snapshots of public places,

technologically touched up

soviet obstacle courses,

they want to invade,

they want to fill our mouths

with medium range missiles,

that is our considered opinion

since, Mt. Panby

is only good for drinking beer

and looking at St. Georges, 
and not even the fishmarket,

it must be our mouths they want to fill

This night

with its shamed faced helicopters

may make it to a poem,

this contra of a night

spilled criminals and machismo

on our mountains,

eagle insignaed somocistas

bared talons in Matagalpa

we were silent in the car,

all that we had talked about

may be gone

and on the way to Mama's bar that night

we stopped, drawn to a radio

on the dark street,

then the woman holding it said

it's the same news,

they're in Nicaragua,

we looked at each other,

someone said, "those bastards."

The street was empty

with all of us standing there

Many years from now

how could it be,

sandflies eat the skin on Mt. Panby beach,

facing the ocean

a look from here can only be a wound,

look! The street empty,

and the bar on Ballast Ground Road

and the beach and the reef

and this little bit,

this bay that only knows

the solitary feet of children

splashing in it on Sundays,

this night may make it to a poem.

Vemos que aquí se simula el tono de diario, no sólo por el título (que también podría remitir a las didascalias de un guion), sino por los primeros versos: «Many years from now / this surf, this night» (95). La necesidad de registro se hace evidente por la repetición de «this night may make it to a poem», lo cual genera un doblez interesante, pues la mano que escribe «may make it to a poem» está creando ese poema. Si en Primitive Offensive se observan juegos de distancias y cercanías en las personas que adoptaba el sujeto imaginario, aquí los entrecruzamientos temporales implican un tratamiento lúdico del registro. «Dentro de muchos años, esta noche podría llegar a ser un poema» sería una posible traducción de la conformación de la primera estrofa. Así, el sujeto lírico se divide entre el que presenta los elementos, es decir, el que se sitúa en esa noche, 
ya pensándola como registro (o al menos como material registrable) y aquel que ya ha registrado el poema «mucho años después». Lo interesante es que la experiencia de esa noche de espera y resistencia está ligada al paisaje. No sólo porque «this surf» está equiparada a «this night» sino porque en paralelo a la tensión, Brand describe el paisaje, pero no como modo de disminuir el nerviosismo sino haciéndolo extensivo a la playa, al cielo y al mar:

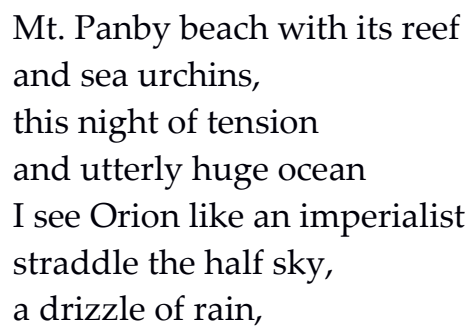

La noche de tensión está equiparada con la amplitud del océano, pero es especialmente interesante el uso de «straddle» (donde la «s» omitida de la tercera persona singular es propia del creole) que genera una ambigüedad estructural. Pues puede tratarse tanto de «cubrir, abarcar» y leerse entonces en «veo a Orión como un imperialista / cubre el medio cielo, / una llovizna», donde se trataría de una inversión en la que el sujeto de «straddle» sería «a drizzle of rain» (una redundancia, por otra parte, pues «drizzle» es «rain») y no Orión. Sin embargo, la comparación de «I see Orion like an imperalist» es tan fuerte que el lector espera que el siguiente verso aclare el anterior; en particular porque la ausencia de coma genera un encabalgamiento, con lo cual la expectativa es que «straddle» (en su acepción de «extenderse a ambos lados») sea el verbo con el que coordina, donde tal vez el «that» está elidido («I see Orion like an imperialist (that) straddle(s) the half sky»). Por ende, se entendería la comparación con una posible alusión al «imperialista» pues «acapara» el cielo. No obstante, creo posible ver ese verso como una mirada general presente en este poemario con respecto al paisaje: la sospecha. Mirar la constelación como a un imperialista es una anticipación de la amenaza que proviene del cielo, el ataque aéreo de la invasión estadounidense, y se genera, además, una contaminación entre amenaza y paisaje que ya está presente desde el título mismo del libro, en el que el sol es hostil, no sólo porque abrasa, sino porque permanecerá impávido frente a la invasión. De este modo, la falta de lluvia implica una alianza con el ataque estadounidense:

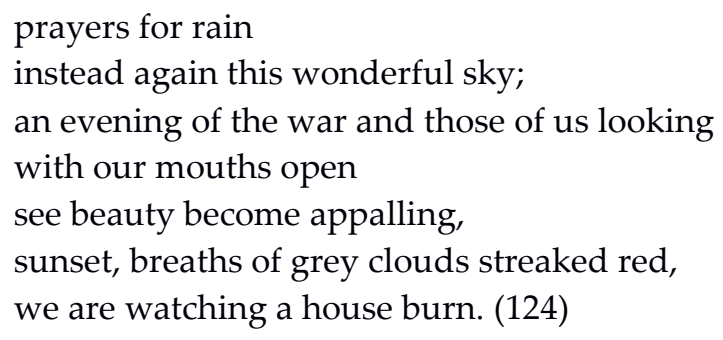


La mirada se reconfigura en «see beauty become appalling», no sólo porque en la belleza del atardecer se vea cómo arde una casa, sino porque el entorno natural se pone en contra de la revolución granadina. ${ }^{7}$ "Wonderful» pierde su connotación positiva al ser lo opuesto a lo que se pide en las plegarias, y las nubes grises no traen la lluvia como se esperaría (expectativa de lector que Brand explota) sino que son la consecuencia del fuego. En el mismo poema, estrofas más adelante se refuerza la idea de la oposición del entorno a la revolución:

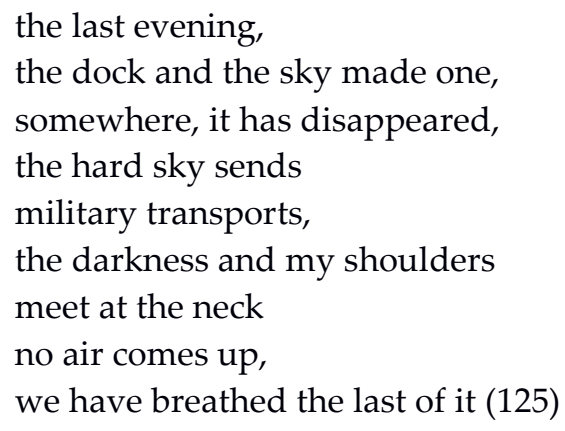

Esta fundición («the dock and the sky make one») permite que se pueda luego situar al cielo como agente que envía «military transports», que no son sólo aviones o helicópteros sino también embarcaciones (pues el cielo y el muelle son lo mismo). Resultaría sencillo describir estos versos como la mera percepción de un sujeto lírico que ve cómo su entorno se transforma ante la invasión militar y todo, el paisaje incluido, se vuelve amenaza. Sin embargo, en una obra como la de Brand, donde lo geográfico resulta tan relevante, los usos del paisaje no son en absoluto ingenuos, sino que deben ser leídos en clave de una escritura topográfica que pone en escena que la artealización paisajística implica una

\footnotetext{
7 En otros poemas se retoma la idea de que la ausencia de lluvia ayudó a la invasión. Así, «October 26th, 1983» (131) se establece que Dios les da la espalda:

A fornight like the one in May

without duplicity

sodden and overcast

we would have held them off a few more days,

god, usually so reliable on matters of hardship

could not summon up a drop of rain

El desprecio a la deidad que los ha dejado librados a su suerte se observa en la utilización de la minúscula y en el sarcasmo de que sólo se pueda confiar («so reliable» en que haga llegar dificultades. La contraposición entre el peso de «hardship» y el humilde «a drop of rain» refuerza la noción de que Dios no es capaz de otorgar algo mínimo. De hecho, se reconoce que la lluvia no hubiera sido ninguna solución, sino que tan sólo les hubiera permitido resistir a los invasores unos días. La indignación contra la lluvia se acrecienta en los dos poemas siguientes, de apenas dos versos cada uno, donde se imita el registro de una entrada en un diario íntimo. Por ello en «October 27th, 1983» se afirma: «And rain does not rust bombers / instead it looks for weaknesses in farm implements» (132) y en «October 27th, 1983 - evening»: «the sky does not have the decency / to shut up» (133). La lluvia queda del lado de los invasores, porque en lugar de atacar los bombarderos, se encarniza con los elementos de trabajo del pueblo. Esto hace que el «have de decency» dé cuenta de la exasperación de la persona poética.
} 
mirada política: desde allí decodifica lo observado. De hecho, aunque esta hostilidad pareciera ser propia de la invasión, en realidad ya se hallaba presente en poemas que referían a la temporalidad previa a la operación «Urgent Fury». Así en «Vieux Fort: St. Lucia» el cielo es calificado siempre negativamente:

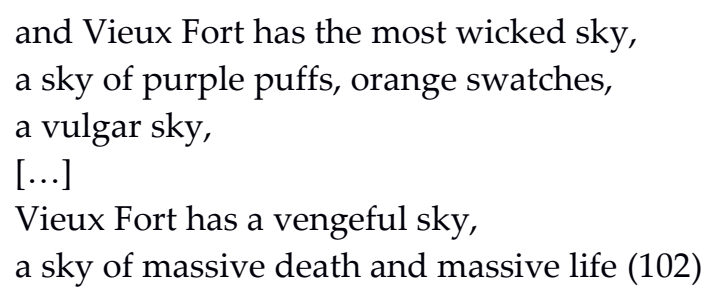

En el siguiente poema, «La Souffriere», el cielo como fuerza negativa que se cierne sobre el sujeto lírico ya no es presentado desde cierta distancia sino desde el padecimiento de la persona poética:

I could feel how close the sky was,

everywhere this persistent sky

I was sitting there with it

tied around my head (103)

Y aunque esta imposibilidad de relacionarse positivamente se presente como una incapacidad propia, criticada como defecto, en «Amelia continued» («[...] I have a vile disposition / it does not appreciate great sunsets/ [...] not even the afternoon sun / escapes my criticism», 118), ${ }^{8}$ en realidad el sentirse amenazada por elementos del paisaje está relacionado con los filtros de su mirada. Desde esta perspectiva, en Chronicles... se pone de relieve mediante la escritura topográfica desde dónde Brand opera la construcción del paisaje. Por ejemplo en «Old Pictures of the New World» (146-147), se mira el paisaje de Barbados pensado en Granada:

1. They show tourists rolling

on beaches in Barbados

someone told me that this island

is flat and inescapable

just right for american [sic] military transports,

this same someone said,

the topography of the island

lacking in gradient or thick forest

gives historical witness to the absence

of slave rebellions

the slaves having nowhere to run

adopted an oily demeanour.

How history slaps us in the face,

using our own hand too.

\footnotetext{
${ }^{8}$ Dado que el título remite a la abuela de Brand, es posible pensar que el sujeto lírico adopta aquí la crítica recibida por parte de Amelia.
} 
Este poema está estructurado en cuatro partes, en las que el primer verso se abre con «they show», donde no se establece claramente quién es el «they», si se refiere a medios de comunicación (en el fragmento 2 se menciona «a full page ad in the Chicago Sun Times», 146), si es una manera genérica de referirse a las imágenes con las que se cubren las noticias sobre la revolución, o si son meras diapositivas que se pasan. El trabajo con la inmaterialidad de las fuentes se ve realzado por la voz de ese «someone» que nunca es definido. «Alguien» pasa información vital para el sujeto lírico, información que es visualmente de fácil comprobación. Elegir que alguien le «diga» lo que claramente se puede observar es una suerte de mediación que recubre de una aparente objetividad. De hecho, la foto prototípica de los turistas al sol en una paya caribeña hace pensar a la persona poética en cómo la geografía atenta contra la revolución. ${ }^{9}$ Así, la elección del adjetivo «inescapable» para describir la topografía de la isla apunta a la imposibilidad de escapar físicamente pero, a su vez, dada la colocación usual con «fate» o «destiny» se exacerba lo «inexorable», poniendo de relieve la geografía como condena ineludible a la revolución, cualquier revolución. ${ }^{10}$

Si bien el «just right for american [sic] military transports» es una crítica al rol de Barbados en la invasión de Granada (uno de los «six Caribbean stooges» [129] del poema «October 25th, 1983») y en cierta medida también a ellos apunta el último verso, pues la imagen de la propia mano que abofetea nos reenvía al Caribe volviéndose contra sí mismo; el hecho de que al observar el paisaje de Barbados se piense en la invasión de Granada y las inexistentes rebeliones de esclavos, va más allá de la reflexión sobre cómo la superficie de un terreno influye sobre la historia o cómo la geografía es un elemento fundamental en la estrategia de una revolución: atestigua que la mirada del sujeto lírico codifica el espacio y construye paisaje a partir de lo político. ${ }^{11}$ Es por ello que sostenemos que en Chronicles of the Hostile Sun la escritura topográfica se observa en la artealización política del paisaje, pues éste no es construido con otra función que la de acompañar la política de localización del sujeto lírico. Rose (1993: 139) retoma este concepto de Adrienne Rich para definir dónde se localiza cualquier sujeto dentro de las matrices de poder discursivas y materiales, y aunque lo piensa en relación a cómo se sitúa el sujeto del feminismo dentro de las complejas relaciones de poder y diferencia, es posible llevarlo a un marco más general que no se limite sólo a la relación con la teoría feminista, sino con la postura

\footnotetext{
${ }^{9}$ Cabe señalar una salvedad a la construcción «prototípica»: la elección del verbo «roll»y no «sunbathing», por ejemplo. La imagen de los turistas rodando en la playa trasmite la idea de retozar pero al mismo tiempo los ridiculiza, como si fueran fardos tirados sobre la arena que no hacen otra cosa que rodar de aquí a allá.

10 Es necesario destacar que el uso que le da Brand aquí a «topografía» no es la descripción del terreno sino las particularidades de éste en sí mismas. Opto por hablar, entonces, de «geografía» para evitar solapamientos con lo que denomino escritura topográfica.

${ }^{11}$ La insistencia de presentar el adjetivo «American» en minúscula, contra la normativa de la lengua inglesa opera como un modo de mostrar el desprecio, de quitarle fuerza o peso al gentilicio. Visualmente, además, evita que la mirada caiga preponderantemente sobre él.
} 
ideológica en general, una que es multidimensional, cambiante y contingente (Rose 1993: 140). En ese sentido, el término poélitica que Chancy (1997) acuña para dar cuenta de la fusión dinámica entre poética y política feminista en la obra de Brand, puede ser ampliado para explorar cómo la mirada poética de nuestra autora está marcada una «ideología visual», en tanto pone de relieve las relaciones de poder que se establecen con el ambiente circundante. Si como sostienen Daniels y Cosgrove (1988) los sentidos del paisaje surgen de los códigos culturales de una sociedad, éstos indefectiblemente estarán imbuidos de las estructuras sociales de poder. De este modo, el paisaje pasa a formar parte de la cultura hegemónica, se convierte en un concepto que ayuda a estructurar la sociedad en relaciones jerárquicas de clase (Rose 1993).

Leemos en la mirada poética de Brand la conciencia de esa estratificación que el paisaje puede ayudar a perpetuar. Así, la conciencia de que la topografía de Barbados es propicia para el envío de tropas está asociada con la imagen paradisiaca de la playa turística (aunque «just right» es más enfático que sólo ser propicia, connota que la isla está concebida para ese fin). No es sólo que lo geográfico configure lo histórico: no existieron revoluciones de esclavos en el pasado, no se apoya las revoluciones del presente (se continúa con una mentalidad de esclavo); sino que esa visión sobre el paisaje implicaría también una renuncia simplificadora, pues explica la falta de lucha en esa realidad inmutable que es la topografía. Barbados estaría, entonces, condenado a perpetuar su historia. La elección de «oily demeanour» para describir la actitud de los esclavos (e indirectamente a la de Barbados frente a Estados Unidos en el conflicto de Granada) apunta, en parte, a una mirada estereotipada de los afrodescendientes en el Caribe que apunta a la obsequiosidad del aparente «buen esclavo», la «jaibería» puertorriqueña, por ejemplo. ${ }^{12}$ Pero además late en «oily» una materialidad innegable, como una capa de aceite que recubre la piel haciendo que todo en ella resbale. Los esclavos se volverían así inmutables. Esa otra connotación latente también apunta al rol de Barbados, pues su ayuda a Estados Unidos implica un desprecio a la lucha granadina.

Por otra parte, si retomamos la frase del epígrafe del presente apartado, vemos que la mirada paisajística se conforma a partir de la «lucha». Es decir, no se puede pensar «the struggle» sin percibirla en términos espaciales: el relato del cual se extrajo la cita describe el retorno de la narradora a la casa de la niñez y la rabia que la consume al ver la «choza» en la que su familia vivía, antigua barraca de esclavos, y la casa del «señor», que rara vez estaba habitada; el presente opera en completa sintonía con el pasado y la misma familia sigue siendo propietaria de esa tierra. En «St. Mary's State» la frase citada implica que la narradora

${ }^{12} \mathrm{Si}$ bien en el Caribe de habla inglesa ese disimulo de sumisión no tiene una palabra que lo denomine, en Puerto Rico se la conoce como «jaibería», tomando el nombre de la jaiba, un tipo de cangrejo común en la zona, pues así como el crustáceo retrocede para avanzar, la jaibería implicaría un rodeo elusivo, una aceptación del orden de cosas que es mero disimulo. La sonrisa del caído que sólo espera su momento para alzarse. 
aprendió del espacio las diferencias de clase (que aquí son además raciales), su paisaje cotidiano le enseñó por qué era necesario luchar. ${ }^{13}$ Aquí nos valemos de la frase para pensar su reverso: si mirar como una paisajista le permitió comprender el grado de desigualdad presente en su sociedad, construir paisaje conlleva para Brand pensar siempre en términos políticos, es decir, para retomar los términos de Roger (2007), los modelos, conscientes o no, que saturan su mirada se construyen a partir de su ideología política que ve en las huellas del paisaje y los espacios habitados el pasado y presente de opresión. De este modo, los códigos de la cultura visual de su «pantalla-tamiz» (Foster 2001: 143) apuntan a relaciones jerárquicas raciales y de clase que se estructuran en la creación de un paisaje. Así como también busca desnudar la que prima en aquellos que encasillan al Caribe dentro de esquemas generales sin hacerse cargo de sus propias contradicciones, como se evidencia en «On Eavesdropping on a Delegation of Conventioners at Barbados Airport» (108-109):

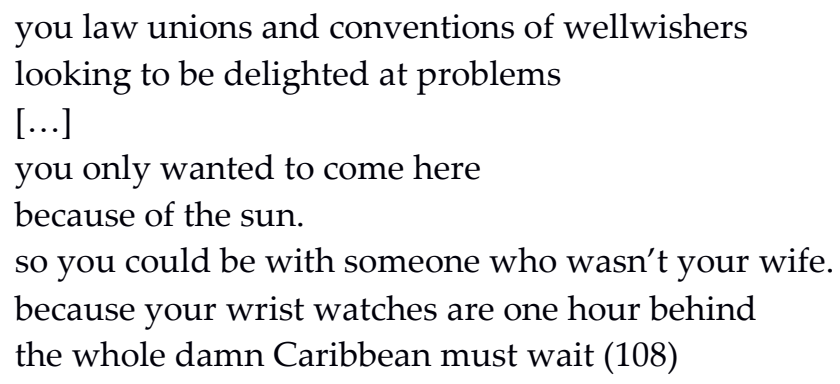

Al igual que se les critica dónde estaba su moralidad y rectitud durante el golpe de estado a Salvador Allende y El Mercurio cubría las noticias como si lo que estuviera ocurriendo no fuera antidemocrático («where were you when they assassinated Allende / and when El Mercurio tried to steal the peoples' revolution»), se presenta su relación con la mirada con la que construyen el Caribe: el sol (ese que para el sujeto lírico es «hostil») y la explotación sexual. ${ }^{14}$ De esta manera se ofrece la belleza del paisaje como mercancía de consumo y como único motivo real, desenmascarando cualquier pretensión de preocupación política, hecho que se refuerza con el «be delighted at problems», donde el sufrimiento de otros se conforma como fuente de excitación. A su vez, se les asigna el lugar de turistas y no de políticos, en el sentido de la «coartada maravillosa» (Barthes 1999: 73) que la calidad de turista ofrece, pues permite «mirar sin comprender, viajar sin interesarse por las realidades políticas» (Barthes 1999: 73).

\footnotetext{
${ }^{13}$ Es desde esta perspectiva que Clarke (2012: 155) afirma que Brand, al establecer la primacía de la geografía -la localización- por sobre la historia como medio que configura consciencia racial y de clases, implica una revisión de los postulados de Marx.

${ }^{14}$ La discusión de fondo presente en este poema, y de allí la comparación con El Mercurio, es que la revolución de Granada no era democrática porque habían cerrado el diario Torchlight en 1979, debate en el que Brand pone de relieve el rol de los medios de comunicación a la hora de desestabilizar gobiernos.
} 
Brand les asigna a estos «conventioners» una mirada simplificadora y controladora del Caribe (que debe ajustarse a los tiempos de ellos), una que no se hace cargo de sus propios prejuicios: tanto con respecto a las Antillas como en términos políticos a la hora de definir qué se entiende por libertad y quién tiene derecho a ella. En ese sentido, el poema siguiente «Eurocentric» (110-111) continúa esa línea crítica, pues la segunda persona a la que se dirige parece ser la misma:

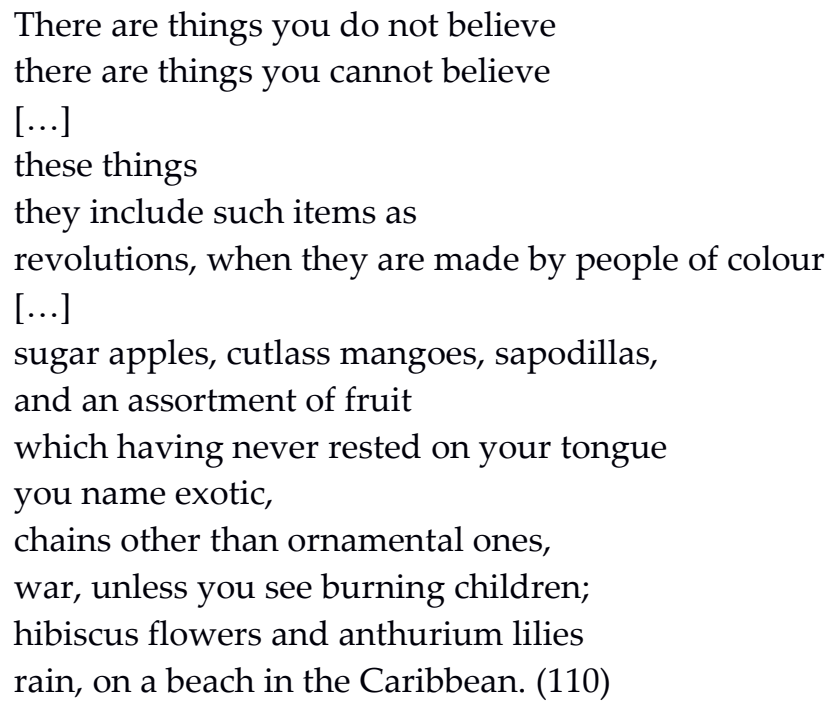

Aquí se observa una crítica a la mirada que no se hace cargo de su propia artealización, todo aquello que se trae a la construcción del paisaje. Los prejuicios estéticos están equiparados a los prejuicios políticos, la misma mirada que construye al Caribe como un paraíso de sol eterno, lleno de riqueza natural, siempre relegado al lugar de lo exótico, es aquella que es incapaz de ver la opresión (las cadenas que no son ornamentales) ni la matanza si no es aquella que esté presentada como un desgarro conmovedor (al igual que versos antes se denuncia que no hay masacre si no hay estadounidenses muertos). De este modo, Brand pone de relieve las relaciones de poder que se esconden detrás de las estetizaciones.

La mirada propia ve siempre desde la revolución (fallida o presente, según en qué temporalidad esté situado el sujeto lírico) ya en «Diary - The Grenada Crisis» (123-125) se establecía que desde Barbados se piensa en Granada, lo curioso es que se generan cruces de temporalidades, pues en ciertas estrofas pareciera que se está en Granada, y luego en Barbados:

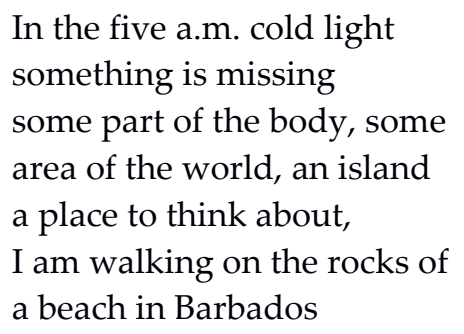


looking to where Grenada was

now, the flight of an American bomber

leaves the mark of a rapist in the room.

En la mente del sujeto lírico Granada ha dejado de existir (de allí el uso del pasado), lo curioso es cómo se percibe esa ausencia: como si parte del cuerpo le faltara. Haber perdido la isla es perder parte del propio cuerpo. Ese tipo de identificación es inusual en Chronicle of..., en el que los filtros de la mirada están siempre presentes y se remarca el carácter de construcción que tiene el paisaje. En «Night - Mt. Panby...» cuerpo y el entorno se funden como lo hace el muelle y el cielo, pues la oscuridad pasa a ser parte del cuerpo al unirse con los hombros («the darkness and my shoulders / meet at the neck»), en un movimiento más propio de su primer poemario, Primitive Offensive, que de Chronicle... Ahora bien, es posible pensar esa fusión en la que el paisaje se vuelve una extensión del sujeto lírico como modo de expresar la nostalgia y la pérdida que genera la separación.

La definición de Granada como «a place to think about» abre camino hacia la nostalgia que surgirá a partir de la invasión. De este modo, Granada será un referente al cual volver, a los años de felicidad que se menciona en «October, 25th, 1983» («[...] you said that for four and a half years, / you have been happy [...]»), un anclaje perdido incluso en el plano mental pues la isla como tal no existe para el sujeto lírico. De esta forma, en «P.P.S. Grenada» (138-145) se evidencia la añoranza, pues Granada es comparada con la abuela: «I am never lonely for anyone / but you» (137) son los versos finales de «P.S. Amelia» y los primeros de «P.P.S. Grenada»: «I have never missed a place either/ except now» (138). En ese poema, el paisaje recuperado, ahora como recuerdo carga consigo la añoranza de esas épocas felices, ha perdido toda amenaza (con la excepción, tal vez del verso «[...] that was when the sea became less / trustworthy», que podría remitir a la invasión en camino). Y si bien no es un paisaje idealizado ni prototípico, sino más bien uno vivido, lo central en el poema es el pasaje que se realiza de lo espacial a la vida cotidiana con otros seres, esas otras personas con las que, en menor o mayor medida se compartía el cotidiano. La isla no es realmente la protagonista de este poema, sino los sujetos que la habitaban. Las relaciones de clase y de poder se entrelazan con la descripción del paisaje. Y no se trataría realmente de una escritura topográfica si leyéramos este poema por sí solo. Sin embargo, en relación con la mirada paisajística que se ha construido hasta llegar a él, aquí algo cambia:

\footnotetext{
but hope, we did not want the newness of this place to end then everyone would lose their memory as in Macondo

it was a new way of seeing everything even though the sky was still oppressive and the land smelled of hardship there was a name for all of this, only
} 
it was never said quite well

but had to do with a freeness which the body felt,

a joy even in the heat (143)

El paisaje que estaba asociado con la amenaza, con la injusticia social, ante el sueño de la revolución cambia en parte de signo, porque la mirada se reconfigura. La «paisajista» ya no mira en términos de lucha como en la cita del epígrafe, es decir, lo que se le devuelve a su mirada no es la hostilidad del paisaje que le recuerda cuál es su lugar en la sociedad, sino que se puede observar con ojos nuevos («the newness / of this place»), más allá de las configuraciones del pasado. Una vez más, la conexión con el espacio implica una relación con el cuerpo: éste lo puede sentir y aquello que en otro momento ha sido asfixiante, puede ser vivido con alegría («a joy even in the heat»). En ese sentido, esa extensión del sujeto lírico en la que el paisaje se convierte está asociado con ese nuevo filtro de la pantalla-tamiz, uno que no anula las dificultades pero ve más allá de ellas («[...] the sky was still oppressive/ and the land smelled of hardship [...]»). Sin embargo, esta relación conciliatoria con el paisaje se da sólo en tanto reminiscencia, como recurso que acrecienta la añoranza, como el placer de nadar y mirar el horizonte no como vía de escape (como ocurrirá en una obra posterior, No Languague is Neutral): ${ }^{15}$

while 1 dove into the water;

just that was enough, so wide, so womanly

the gaze to the horizon,

I would forget to fill my lungs

for hours, looking to this sea,

Se observa un estado de armonía con el entorno que parece sustentarla al punto que respirar se vuelve innecesario (en contraposición a «Diary - The Granada Crisis» donde ya no quedaba más aire). El mar lo abarca todo y la fascinación que genera está asociada con la paz. El uso del deíctico en «this sea» acerca al sujeto lírico a la escena, haciéndonos olvidar momentáneamente que se

\footnotetext{
${ }^{15}$ En ese poemario se afirma:

The smell of hurrying passed

my nostrils with the smell of sea water and fresh fish

wind, there was history which had taught my eyes to

look for escape even beneath the almond leaves fat

as women, the conch shell tiny as sand, the ruck

stone old like water. (19)

Y en el poema «Return II»

every eye looking out of its black face many years

ago must have longed to dive into the sea woman's

belly swimming to away only to find

Pointe Galeote's nubbly face

back to there and no further than the heat flush (12)

Se establece, así, que se mira al paisaje en clave de fuga, en la posibilidad de huir.
} 
trata de un recuerdo. ${ }^{16}$ De esta forma, Brand aumenta la brutalidad que conlleva el retorno al presente en el que el sueño de la revolución ha desaparecido:

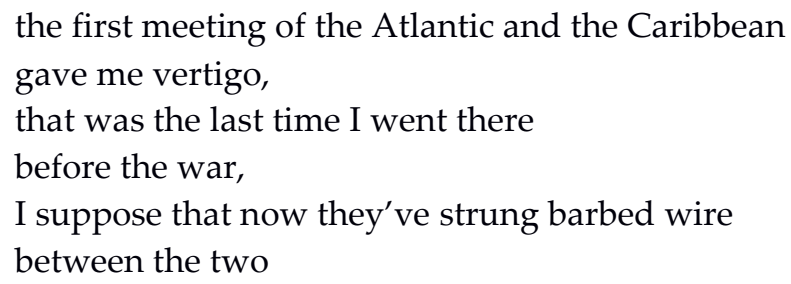

La imagen del mar Caribe fundiéndose con el Atlántico remite en parte al Middle Passage [la travesía forzada de los esclavos por el Atlántico], que es para Brand el único sitio de pertenencia real. ${ }^{17}$ Sin embargo, aquí también está asociado con la unión entre el Caribe y el resto del mundo. El alambre de púa señala un ostracismo, la isla convertida en una suerte de prisión, y al mismo tiempo, la imagen remite a que aquello que en Brand está asociado con el origen (doloroso pero aun así una pertenencia a la cual aferrarse). Éste se vuelve ajeno, es decir, queda atrapado, el yo lírico tiene prohibido el acceso. Aunque no son los versos finales del poema, lo son del fragmento y se cancela ferozmente la armonía retratada: si la revolución permitía adquirir otra manera de mirar el paisaje y por ende otra forma de relacionarse con él, la invasión estadounidense pondrá un fin a esa otra mirada con toda la violencia de un alambre de púa. ${ }^{18}$

El cierre de este largo poema opera desde el tópico del abandono, la renuncia, que se encuentra tanto en dejar el sombrero regalado por el garifuna (muestra del fracaso de la hermandad construida) ${ }^{19}$ como en la lista de objetos «my roads, my evenings» $y$, por supuesto, el paisaje:

\footnotetext{
16 Esto crea cierta incoherencia entre el uso del pasado y «this», pues ese tiempo verbal demandaría el uso de «that».

${ }^{17}$ En The Map to the Door of No Return (2001) libro de ensayo autobiográfico, el Middle Passage es la «Puerta de No Retorno»: esa tumba colectiva que es el mar será para Brand el único hogar posible.

${ }^{18}$ Cabe destacar que aquí también está latente una referencia histórica: Maurice Bishop llevó a cabo una protesta en 1973 porque la playa Brown estaba cerrada al público.

19 En el poema «Carifuna» (100) se plantea un encuentro entre afrodescendientes y pueblos originarios y se establece una hermanad que trasciende el tiempo:

This ancient Carib sold me a hat

and sent his ancient son with a gift

for me,

our spectacles did not hide our ancient look,

those ships...

discovered and killed us both

now we shared the trinkets left.

$[\ldots]$

I left them in the mountain road, and I took them with me.

Abandonar el sombrero a la hora de partir, implica también la renuncia a esa hermandad.
} 
the sea in the night, that part which

the lights outside the Dome make clear,

is warm

warmer than the air, and the water

becomes something other than water, fog,

it rolls, rather, spreads toward the feet.

Aquí no hay brutalidad, sino más bien una suerte de ensoñación. Lo interesante es el uso, por primera vez en el poema, del presente, como si el sujeto lírico viera delante de sí lo que describe. Se genera, de esta forma, cierto rechazo respecto del abandono, es decir, la isla que parecía haber dejado de existir para la persona poética sigue teniendo carnadura. No obstante, se observa cierta disolución en esta imagen final, cierto carácter nebuloso en la imagen, como una fotografía fuera de foco o esfumada. En ese sentido, la repetición constante que hace Brand durante todo el largo poema de «there was», que no apunta sólo a elementos sino también a los recuerdos en sí («there was a night swimming in the dark», por ejemplo), como si estos se volvieran objetos que se acumulan, o como si cada elemento se transformase en una suerte de foto que el sujeto lírico va pasando y describiendo, opera hasta aquí aportando definición, nitidez visual, hecho que parece disolverse en la última imagen. Tal vez esto obedezca a que el agua pasa a ser otra cosa, a ese esparcirse en los pies («spreads») o tal vez a la mención a la niebla, que hace que todo el cierre se vuelva nebuloso, como si el recuerdo quedase teñido de ensueño.

La reapropiación de las imágenes se hace evidente en el siguiente poema, «Old pictures...» (146-147) ya antes mencionado. Así, las fotos que el sujeto lírico presenta se contraponen con las construidas en el poema anterior. El epítome parece encontrarse en el poema «3», en la que un niño granadino comparte una naranja con un soldado estadounidense, situación a la cual el sujeto lírico define como la «nueva postal», la «nueva mirada para el nuevo colonialismo», que restablece la mirada exotizante y tranquilizadora, la recuperación de un orden regulador («now we know our place», se dice en el fragmento «6»). Sin embargo, el poema final de «Old pictures...» (146-147) derrumba cualquier fantasía de resignación:

9. they think that I'll forget it

but I won't

and when they think that I've forgotten

they will find a note in the rubble

of the statue of liberty.

Resulta particularmente fructífero ahondar en el «it» de «forget it». ¿Cuál sería su referente? ¿La revolución?, ¿la invasión?, ¿Granada misma? Todas las opciones son posibles. El acto terrorista de destruir el símbolo estadounidense por excelencia, la Estatua de la Libertad, puede ser leído como una acción más del movimiento revolucionario y también como venganza hacia los Estados 
Unidos. Si en el poema anterior, la última imagen nos llevaba al ensueño, a algo difuso que se esfuma frente a los ojos, aquí se establece la voluntad de no olvidar. De esta forma, en el cierre en «5th Anniversary» se le otorga a Granada la categoría de «hogar»; no obstante, el alegato de resistencia en el poema «9» de «Old pictures...» (147) resulta refutado en los últimos versos del poemario: «things would happen now, without me», donde la coma establece una fuerza mayor entre continuidad y quiebre; continuidad de la historia, quiebre porque se renuncia a participar en ella.

\section{FRACASO, RENUNCIAS Y LA MIRADA DE UNA PAISAJISTA}

Chronicles... es el relato de la derrota. El fracaso del sueño revolucionario también es el quiebre de la hermandad debido a la doble traición interna: la de una facción dentro del propio gobierno revolucionario y la de los otros países caribeños al aliarse a Estados Unidos en la operación Urgent Fury.

En este poemario pareciera existir la fantasía de haber hallado un lugar de pertenencia, de allí que en breves instancias el paisaje pueda ser visto como una extensión del sujeto lírico, que Granada sea el único lugar por el que se sienta nostalgia (de hecho se lo compara con la abuela, figura recurrente en la poesía de Brand) y que recibe sobre el final del libro el nombre de «hogar». Esa pertenencia, que podría leerse como un anclaje, es destruido con la invasión estadounidense, y lleva a la escritura del siguiente poema, varias veces mencionado por la crítica (aunque sea en análisis de otros libros).

\footnotetext{
I am not a refugee,

I have my papers,

I was born in the Caribbean

practically in the sea,

fifteen degrees above the equator,

I have a canadian [sic] passport,

I have lived here all my adult life,

I am stateless anyway (157)
}

La renuncia a un Estado, conjuntamente con las nociones geopolíticas, territoriales e históricas que esta categoría conlleva, no es sólo la aceptación de la pérdida del hogar, implica asimismo la renuncia a un anclaje, hecho que se volverá tema recurrente de la obra posterior de Brand. En ese sentido, el fracaso de ese proyecto político y estético («poelítico» como lo denominaría Chancy 1997) será el «infierno» que Brand deberá atravesar, según las palabras de Clarke (2012), para alcanzar la madurez de su estilo, pero será también una herida que reaparecerá constantemente en sus libros: la imposibilidad de apostar por el sueño revolucionario. En ese sentido, Chronicles of a Hostile Sun resulta vital para pensar la obra de Brand, pese a que la crítica no lo haya analizado en profundidad y a que ciertas características típicas de su estilo poético no se observen en él (los 
versos largos y encabalgados, las extensas enumeraciones, un ritmo urgente que a amenaza con dejar sin aire al lector), pues establece no sólo un motivo recurrente, sino que da cuenta desde dónde se sitúa Brand para configurar no sólo el paisaje, sino toda su poesía. La pantalla-tamiz o su política de localización se haya siempre en la lucha de clases y discriminación racial: mirar como una paisajista implica ver la huella constante de las diferencias en todo aquello que la rodea, incluso (o especialmente) en la artealización que esconde bajo el manto estético las más lacerantes desigualdades.

\section{BIBLIOGRAFÍA}

ADORNO, T. (2004 [1970]), Teoría Estética, Ediciones Akal, Madrid.

BARTHES, R. (1999), Mitologías, Buenos Aires, Siglo XXI.

BAUGH, E. (2001), "A History of Poetry», en A History of Literature in Caribbean English and Dutch Speaking Regions, James Arnold, A., vol. 2, Amsterdam/Filadelfia, John Benjamins Publishing Company, 227-282.

BRAND, D. (2011), Chronicles of the Hostile Sun, en Chronicles, Early Works, Waterloo, Canadá, Wilfrid Laurier University Press.

BRAND, D. (1998), No Language Is Neutral, Ontario, McClelland \& Stewart.

BRAND, D. (2001), A Map to the Door of No Return, Ontario, McClelland \& Stewart.

BenÍTEZ Rojo, A. (1998), La isla que se repite, Edición definitiva, Barcelona, Editorial Casiopea.

BERGER, J. (2000 [1972]), Modos de ver, Barcelona, Editorial Gustavo Gili.

BRATHWAITE, K. Y GLISSANT, E. (2010), «El lenguaje-nación y la poética del acriollamiento. Una conversación entre Kamau Brathwaite y Édouard Glissant», en Memorias del silencio: literaturas en el Caribe y Centroamérica, Phaf-Rheinberger, I. (ed.), Salto, G. (edición, compilación y prólogo), Buenos Aires, Corregidor, 17-44. (trad. Benavente Morales, C., «Nation languageand poeticsofcreolization.Aconversation between Kamau Brathwaite and Édouard Glissant», en Phaf Rheinberger (ed.), Memorias de la fragmentación. Tierra de libertad y paisajes del Caribe, BerWn, ViNB, 115-130.

BReINer, L. (1998), An Introduction to West Indian Poetry, Cambridge, Cambridge University Press.

BRYSON, N. (1988), «The Gaze in the Expandend Field», en Vision and Visuality, Foster, H. (ed.), Seattle, Bay Press.

CHANCY, M. (1997), Searching for Safe Spaces: Afro-Caribbean Women Writers in Exile, Philadelphia, Temple University Press.

Clarke, G. (2012), Directions Home: Approaches to African-Canadian Literatures, Toronto, University of Toronto Press.

Cosgrove, D. (1984), Social Formation and Symbolic Landscape, Madison Wisconsin, The University of Wisconsin Press.

CosGrove, D. (2002), «Observando la naturaleza: el paisaje y el sentido europeo de la vista», Boletín de la Asociación de Geógrafos Españoles, 34, 63-89.

COSGROVE, D. (2004), «Landscape and landschaft», en Boletín del Germanic History Institute, 35 (otoño). Recuperado de: <http://www.ghi-dc.org/publications 
/ghipubs/bu/035/35.57.pdf>.

COSGROVE, D. (2002), «Observando la naturaleza: el paisaje y el sentido europeo de la vista», Boletín de la Asociación de Geógrafos Españoles, 34, 63-89.

CRARY, J. (1988), «Modernizing Vision», en Vision and Visuality Foster, H. (ed.), Seattle, Bay Press.

DANIELS, S. Y COSGROVE, D. (1988), The iconography of landscape: essays on the symbolic representation, design and use of past environments, Cambridge, Cambridge University Press.

FOSTER, H. (1988), Vision and Visuality, Seattle, Bay Press.

GLISSANT, É. (1997 [1981]), Le discours antillais, París, Éditions Gallimard.

GLISSANT, É. (2006 [1997]), Tratado de todo-mundo, Barcelona, El Cobre ediciones.

JAY, M. (1988), «Scopic Regimes of Modernity», en Vision and Visuality, Foster, H. (ed.), Seattle, Bay Press.

MAsiello, F. (2013), El cuerpo de la voz (poesía ética y cultura), Rosario, Beatriz Viterbo Editora.

MilLeR, HILLIS, J. (1995), Topographies, Stanford, Stanford University Press.

PedreIRA, A. (1942 [1934]), Insularismo, San Juan de Puerto Rico, Biblioteca de autores puertorriqueños.

PIZARRO, A. (comp.) (2002), El archipiélago de fronteras externas, Santiago, Editorial de la Universidad de Santiago de Chile.

RoGer, A. (2007), Breve tratado del paisaje, Madrid, Biblioteca Nueva.

Rose, G. (1993), Feminism and Geography: The Limits of Geographical Knowledge, Minneapolis, University of Minnesota Press.

SilvestRI, G. y AliATA, F. (2001), El paisaje como cifra de armonía, Nueva Visión, Buenos Aires.

SouTO, P. (coord.) (2001), Territorio, Lugar, Paisaje. Prácticas y conceptos básicos en geografía, Colección Libros de Cátedra, Buenos Aires, Facultad de Filosofía y Letras, UBA.

Williams, R. (2001), El campo y la ciudad, Buenos Aires, Paidós. 